\title{
$\angle$ Review
}

\section{Synthesis of Non-canonical Amino Acids and Peptide Containing Them for Establishment of the Template for Drug Discovery}

\author{
Tsubasa Inokuma \\ Graduate School of Biomedical Sciences, Tokushima University; \\ 1-78-1 Shomachi, Tokushima 770-8505, Japan. \\ Received January 11, 2021
}

\begin{abstract}
Non-canonical amino acid derivatives are an attractive scaffold for novel drug candidates. Among the methods used to prepare this motif, the asymmetric Mannich-type reaction of $\alpha$-imino carboxylic acid derivatives is a preeminent strategy because a wide variety of non-canonical amino acids can be accessed by changing only the nucleophile. Preparing the common substrate is difficult, however, which makes this method problematic. We developed a convenient method for synthesizing common substrates using $\mathrm{MnO}_{2}-$ mediated oxidation of stable precursors. Peptides bearing non-canonical amino acids are another attractive synthetic target. We propose a new approach for synthesizing non-canonical amino acid-containing peptides by directly applying various organic reactions to peptidic substrates. Using hydrophobic anchor-supported peptides, we directly applied ring-closing metathesis and asymmetric Friedel-Crafts reactions to peptidic substrates. We also developed a novel recyclable organocatalyst according to the nature of the hydrophobic anchor tagged compound.
\end{abstract}

Key words non-canonical amino acid derivative; peptide; $\alpha$-amino phosphonic acid; hydrophobic anchor; recyclable organocatalyst

\section{Introduction}

Non-canonical amino acids and related compounds are promising novel drug candidates. ${ }^{1,2}$ These compounds can also be used as chiral building blocks for asymmetric catalysts $^{3)}$ or structurally complex natural products, ${ }^{4-6)}$ and in this context, much effort has been put forth toward their development. $\alpha$-Hydrazination of carbonyl compounds ${ }^{7)}$ and the asymmetric Strecker reaction ${ }^{8)}$ are widely used strategies for synthesizing non-canonical amino acid derivatives and several asymmetric catalysts for those reactions have been reported. These strategies require different substrates for the preparation of various non-canonical amino acids with different side-chain structures. One example of this is asymmetric $\alpha$-alkylation of the iminoester derived from benzaldehyde and glycinate catalyzed by a phase transfer catalyst. ${ }^{9)}$ This procedure is a robust methodology for installing an $s p^{3}$ carbon-centered substituent into a side chain structure from a common substrate by changing only the electrophiles used. As another example, an asymmetric Mannich-type reaction using $\alpha$-imino ester was developed. ${ }^{10-14)}$ Also in this procedure, various types of noncanonical amino acids are prepared from a common substrate. This procedure allows for the introduction of not only the $s p^{3}$ carbons, but also $s p^{2}$ carbons. The present review describes

This review of the author's work was written by the author upon receiving the 2020 Pharmaceutical Society of Japan Award for Young Scientists. our recent progress toward the development of novel methods for synthesizing non-canonical amino acid derivatives via an asymmetric Mannich-type reaction of $\alpha$-imino carboxylic acids. Achievements toward the development of a novel recyclable catalyst based on this research are also described.

\section{Synthesis of Small Molecule Non-canonical Amino Acid Derivatives}

2.1. Synthesis of Non-canonical Amino Acid Derivatives Using $N$-p-Methoxyphenyl ( $N$-PMP) Imino Carboxylic Acids One drawback of the conventional strategy using an asymmetric Mannich-type reaction of $\alpha$-imino carboxylic acids is the difficulty in preparing the common substrate. The common substrate is prepared from glyoxalate, which is easily polymerized or hydrolyzed. The aldehyde is condensed with one equivalent of the appropriate primary amine, and the resulting imine is used without further purification because of the instability of this compound under standard silica gel column chromatography conditions. Therefore, the purity of each lot varies, which hinders the accumulation of a stable supply of starting materials for synthesizing the non-canonical amino acids. It was recently reported that the same compound can be generated by oxidizing relatively stable $N$-PMP glycinate using a homogeneous oxidant such as 2,3-dichloro-5,6dicyanobenzoquinone, ${ }^{15)}$ or tert-butyl hydroperoxide. ${ }^{16)}$ Even molecular oxygen can be used for this purpose in the presence 
Table 1. Preparation of $N$-PMP $\alpha$-Imino Carboxylic Acid Derivatives via Oxidation of $N$-PMP Glycine Derivatives Using $\mathrm{MnO}_{2}{ }^{\mathrm{a}}$

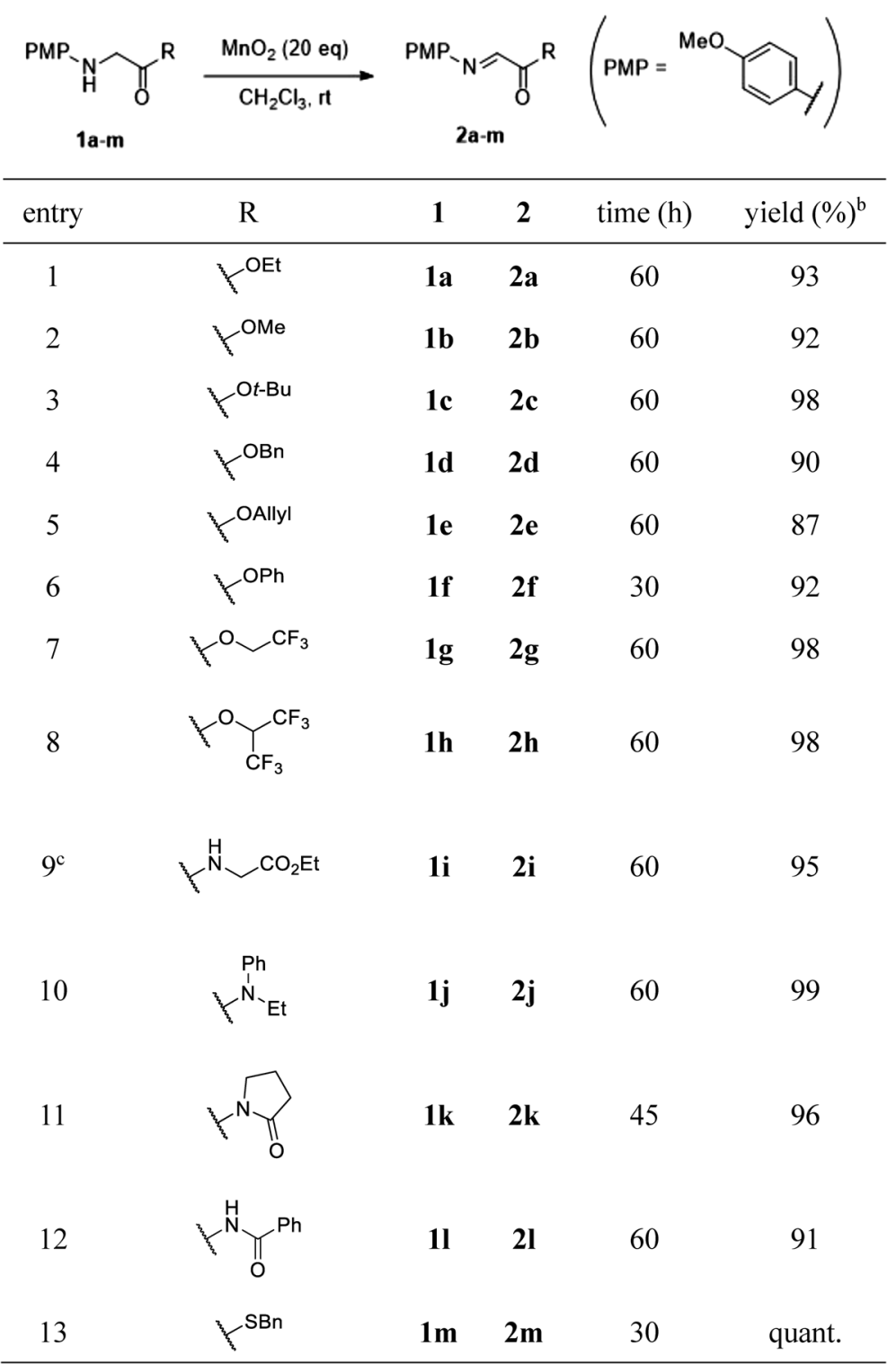

${ }^{a}$ The reaction was performed with 1 (1.0 equiv) and $\mathrm{MnO}_{2}$ (20 equiv) in $\mathrm{CH}_{2} \mathrm{Cl}_{2}$ at room temperature. ${ }^{b}$ Isolated yield. ${ }^{\mathrm{c}} 25$ equiv of $\mathrm{MnO}_{2}$ was used.

\section{Biography}

Tsubasa Inokuma was born in 1983 in Okayama, Japan. He received his B. S. (2005) and M. S. (2007) degree from Kyoto University under the guidance of Prof. Yoshiji Takemoto. In 2008, he became a designated assistant professor in Kyoto University and received his Ph.D. in 2011 from Kyoto University under the supervision of Prof. Yoshiji Takemoto. After working as a Research Associate of Professor Carlos F. Barbas III's group at The Scripps Research Institute, he moved to Tokushima University and joined Prof. Akira Otaka's group as a designated assistant professor. In 2017, he became an assistant professor of Prof. Ken-ichi Yamada's research group. He received the Shionogi \& Co., Ltd. Award in Synthetic Organic Chemistry, Japan (2016), Young Investigator Award of the

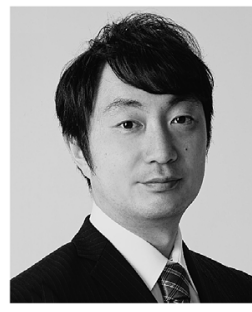

Tsubasa Inokuma Pharmaceutical Society of Japan, Chugoku-Shikoku Branch (2017), and the Pharmaceutical Society of Japan Award for Young Scientists (2020). His research interests include the development of new and efficient methodologies for synthesizing biologically important molecules. 
of a designed $N$-oxyl radical-type catalyst. ${ }^{17)}$ These reactions can be coupled with an asymmetric Mannich-type reaction by adding the nucleophile and asymmetric catalyst in a one-pot manner. ${ }^{15,17)}$ Although this strategy is excellent for synthesizing non-canonical amino acids, the asymmetric reaction must be applied in the presence of oxidants. Therefore, the catalyst system must be tolerant to oxidative conditions. We hypothesized that if the oxidant could be removed from the reaction mixture without performing silica gel column chromatography, we could readily obtain the $\alpha$-imino ester substrate and use the common substrate in the absence of an oxidant. Therefore, we performed the oxidation of $N$-PMP imino ester using an easily removable oxidant ${ }^{18}$ (Table 1). We selected $\mathrm{MnO}_{2}$ as the oxidant. When we began our research, $\mathrm{MnO}_{2}$-mediated construction of the $\mathrm{C}=\mathrm{N}$ bond by oxidation of an amine substrate had been reported in some cases, such as in the formation of nitrogen-containing aromatic heterocycles, ${ }^{19,20)}$ but not for the synthesis of $\alpha$-imino esters. When $N$-PMP glycine ethyl ester 1a was treated with $\mathrm{MnO}_{2}$, the oxidation smoothly proceeded, and the desired imino ester 2a was obtained by simple filtration (entry 1 ). This reaction was widely applicable to various esters and amides (entries 2-5, 9, 10). Using the phenyl ester 1f, perfluoroalkyl ester $\mathbf{1 g}, \mathbf{h}$, and imides $\mathbf{1} \mathbf{k}$, $\mathbf{I}$ as the substrates, we prepared highly activated imino carboxylic acid derivatives $\mathbf{2 f -}-\mathbf{h}, \mathbf{k}, \mathbf{l}$ in good yields (entries 6-8, 11, 12). Surprisingly, thioester $\mathbf{1 m}$ was also tolerated, and the corresponding imino thioester $\mathbf{2} \mathbf{m}$ could be obtained quantitatively (entry 13).

Having extended the availability of imino carboxylic acids bearing various carboxylic acid moieties, we next applied the obtained imines 2 to an asymmetric Mannich-type reaction of 1,3-dicarbonyl compound $\mathbf{3}$ catalyzed by bifunctional amino thiourea catalyst $4^{21)}$ developed by Takemoto (Table 2). Although the conventional simple ester-type substrate $\mathbf{2 a}$ gave

Table 2. Asymmetric Mannich Reaction Using N-PMP Imino Carboxylic Acid Derivatives Catalyzed by Aminothiourea-Type Organocatalyst $\mathbf{4}^{\text {a }}$

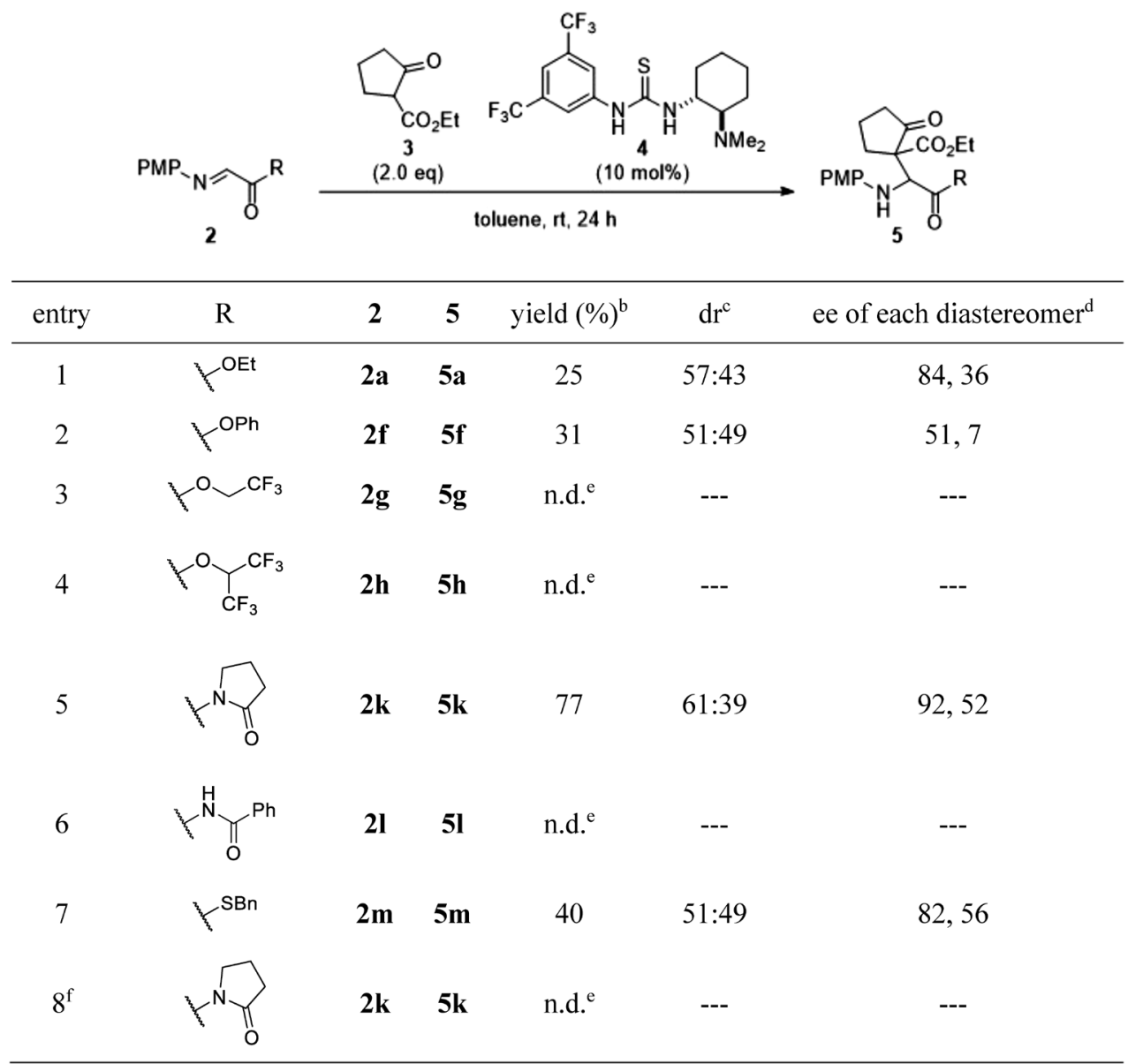

${ }^{a}$ The reaction was performed with 2 (1.0 equiv), 3 (2.0 equiv), and 4 (10 mol\%) in toluene at room temperature for $24 \mathrm{~h}$ ${ }^{\mathrm{b}}$ Isolated yield. ${ }^{\mathrm{c}}$ Estimated by chiral HPLC analysis. ${ }^{\mathrm{d}}$ Determined by chiral HPLC analysis. ${ }^{\mathrm{e}}$ Not detected. ${ }^{\mathrm{f}}$ The reaction was performed in the presence of $\mathrm{MnO}_{2}$.

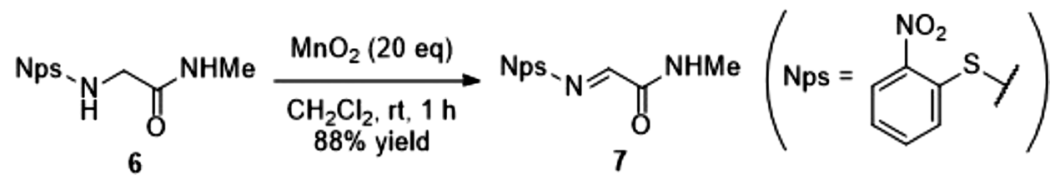

Chart 1. Preparation of $\mathrm{N}$-Nps Imino Amide via $\mathrm{MnO}_{2}$-Mediated Oxidation 
Table 3. Asymmetric Friedel-Crafts Reaction of $N$-Nps Imino Amide $7^{\text {a }}$
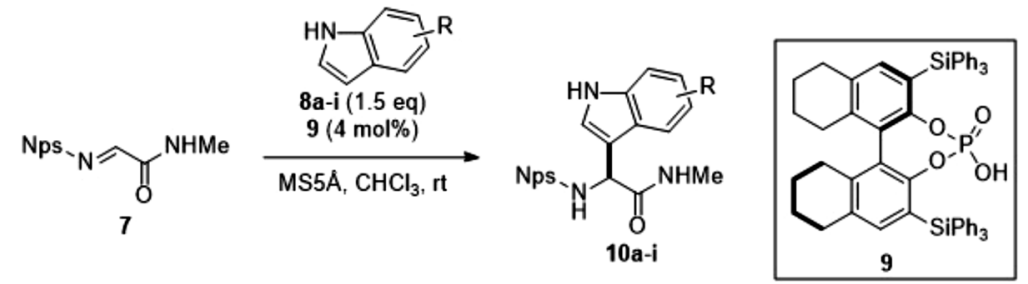

\begin{tabular}{|c|c|c|c|c|c|c|}
\hline entry & indole & 8 & 10 & time (h) & yield $(\%)^{b}$ & ee $(\%)^{\mathrm{c}}$ \\
\hline 1 & & $8 \mathbf{a}$ & $10 \mathrm{a}$ & 4 & 82 & 80 \\
\hline 2 & & $8 b$ & $10 \mathrm{~b}$ & 4 & 76 & 77 \\
\hline 3 & & $8 c$ & $10 \mathrm{c}$ & 24 & 52 & 85 \\
\hline 4 & & $8 d$ & 10d & 4 & 70 & 81 \\
\hline 5 & & $8 e$ & $10 \mathrm{e}$ & 4 & 65 & 70 \\
\hline 6 & & $8 f$ & $10 f$ & 4 & 92 & 77 \\
\hline 7 & & $8 g$ & $10 \mathrm{~g}$ & 4 & 99 & 79 \\
\hline 8 & & $8 \mathrm{~h}$ & $10 \mathrm{~h}$ & 4 & 95 & 93 \\
\hline 9 & & $8 \mathbf{i}$ & $10 i$ & 18 & 72 & 45 \\
\hline
\end{tabular}

${ }^{\mathrm{a}}$ The reaction was performed with 7 (1.0 equiv), 8 (1.5 equiv), MS5 $\AA$, and 9 ( $\left.4 \mathrm{~mol} \%\right)$ in $\mathrm{CHCl}_{3}$ at room temperature. ${ }^{\mathrm{b}}$ Isolated yield. ${ }^{\mathrm{c}}$ Determined by chiral HPLC analysis.
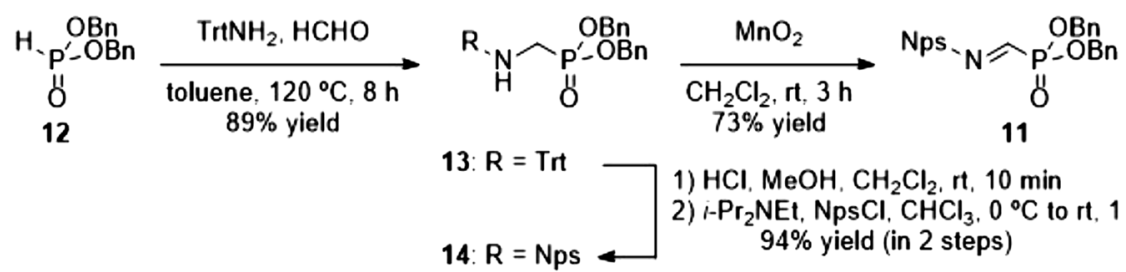

1) $\mathrm{HCl}, \mathrm{MeOH}, \mathrm{CH}_{2} \mathrm{Cl}_{2}, \mathrm{rt}, 10 \mathrm{~min}$ 2) $i-\mathrm{Pr}_{2} \mathrm{NEt}, \mathrm{NpsCl}, \mathrm{CHCl}_{3}, 0^{\circ} \mathrm{C}$ to $\mathrm{rt}, 1 \mathrm{~h}$

14: $R=$ Nps

$94 \%$ yield (in 2 steps)

Chart 2. Preparation of $N$-Nps Imino Phosphonates

adduct 5a with good enantioselectivity, the chemical yield and diastereoselectivity were low (entry 1). To improve the yield, we tested activated esters $\mathbf{2} \mathbf{f}-\mathbf{h}$. The yield was not improved by using phenyl ester $\mathbf{2} \mathbf{f}$ and no adducts were observed in the reaction using perfluoroalkyl esters $\mathbf{2 g}$, h (entries 2-4). Imide-type substrate $\mathbf{2 k}$, however, gave the desired adduct $\mathbf{5 k}$ in improved chemical yield with high enantioselectivity (entry 5). On the other hand, another imide-type substrate 2 I did not produce adduct $\mathbf{5 l}$ (entry 6). Although the reason for the improved result when using $\mathbf{2} \mathbf{k}$ is unclear, the position and orientation of the carbonyl group on the 5-membered ring system might preferentially act to form a ternary complex of 
the substrate, nucleophile, and catalyst. Thioester $\mathbf{2} \mathbf{m}$ afforded comparable results to simple ester $\mathbf{2 a}$ (entry 7). We successfully expanded the scope of the reactions for synthesizing noncanonical amino acid derivatives by extending the availability of the precursors. The reaction using $\mathbf{2} \mathbf{k}$ as the substrate did not proceed in the presence of $\mathrm{MnO}_{2}$ due to decomposition of catalyst 4 . This result indicates the importance of removing the oxidant after forming the imine substrate (entry 8).

2.2. Synthesis of Non-canonical Amino Acid Derivatives Using $N$-2-Nitrophenylsulfenyl ( $N$-Nps) Imino Carboxylic Acids Another problem in synthesizing amino acids using $N$-PMP imino carboxylic acid derivatives is the difficulty in deprotecting the amino group. Harsh oxidative conditions, such as using cerium ammonium nitrate ${ }^{22)}$ or hypervalent iodane oxidant, ${ }^{23)}$ are used to remove the PMP group. Rutjes recently reported that the PMP group could be removed using relatively mild oxidants such as periodic acid or trichloroisocyanuric acid, but the reaction requires $\mathrm{H}_{2} \mathrm{SO}_{4}$ to progress. ${ }^{24)}$ In this context, we attempted to use a readily removable protective group rather than a PMP group. Among the protective groups for primary amines, we focused on the 2-nitrophenylsulfenyl (Nps) group. The Nps group was first introduced by Zervas as a protective group for primary amines in $1963 .{ }^{25)}$ The Nps group can be removed by mild nucleophilic conditions. ${ }^{26,27)}$ We envisioned that if $N$-Nps imino carboxylic acid could be prepared similarly to $N$-PMP variants, this would provide another option for synthesizing non-canonical amino acids. ${ }^{28)}$ Fortunately, oxidation of $N$-Nps glycine amide 6 was achieved similarly to the preparation of $N$-PMP imines 2 (Chart 1). The resulting $N$-Nps imino amide 7 was stable under silica gel conditions and could be purified by simple column chromatography, unlike the $N$-PMP variants.

We applied $N$-Nps imino amide 7 to an asymmetric Friedel-Crafts reaction of indole nucleophiles $\mathbf{8}$ in the presence of 1,1'-bi-2-naphthol (BINOL)-derived chiral Brønsted acid catalysts $^{29,30)}$ (Table 3). The reaction of 7 and non-substituted indole 8a proceeded smoothly in the presence of $3,3^{\prime}-\mathrm{SiPh}_{3}$ substituted catalyst 9 and the corresponding adduct 10a was obtained with good enantioselectivity (entry 1). Both electronrich indole $\mathbf{8 b}$, e and electron-deficient indoles $\mathbf{8 c}$, $\mathbf{d}$ can be used (entries 2-5). We also examined the effect of the substituent position and found that indoles $\mathbf{8 f}-\mathbf{h}$ were tolerated (entries 6-8). On the other hand, 2-methylindole 8i did not give the corresponding adduct $\mathbf{1 0} \mathbf{i}$ with sufficient enantioselectivity (entry 9).

2.3. Synthesis of Chiral Amino Phosphonic Acid Derivatives Using $N$-Nps Imino Phosphoate Chiral $\alpha$-amino phosphonic acids comprise another example of biologically active compounds because the phosphonic acid amide moiety acts as a transition state analog of the hydrolyzed intermediate of the peptide bond. ${ }^{31)}$ Although several preparative methods involving the asymmetric addition of nucleophiles to $\mathrm{N}$ protected $\alpha$-imino phosphonates as universal precursors have been established, they require unstable substrates and/or hazardous reagents. ${ }^{32-34)}$ We anticipated that our reaction could be applied to the synthesis of amino phosphonic acid derivatives by switching the carboxylic acid moiety to phosphonate. ${ }^{35)}$ The corresponding $N$-Nps imino phosphonate 11 was readily prepared using dialkyl phosphite 12 (Chart 2). A three-component Mannich-type reaction of $\mathrm{TrtNH}_{2}$, paraformaldehyde, and

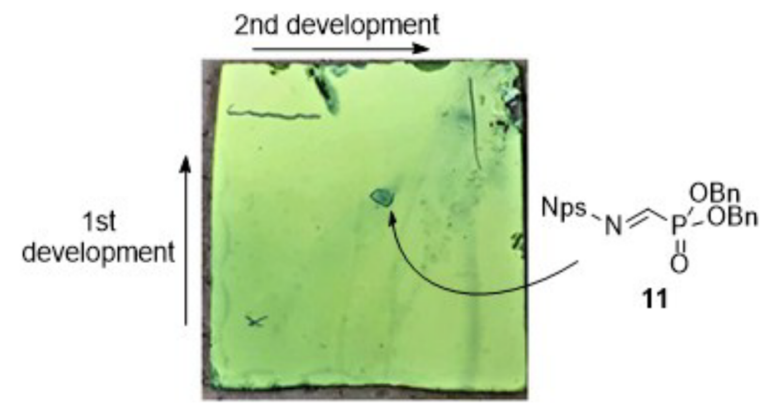

Fig. 1. Two-Dimensional TLC Development of $\mathbf{1 1}$

(Color figure can be accessed in the online version.)

12 gave $N$-Trt-protected aminomethyl phosphonate $\mathbf{1 3}$ in good yields. The Trt group was then exchanged with an Nps group by one-pot acid treatment and $\mathrm{Nps}$ protection. $\mathrm{MnO}_{2}$ successfully oxidized the resulting Nps-protected intermediates 14 to afford the corresponding imino phosphonate 11. As expected, imino phosphonate $\mathbf{1 1}$ was also stable under standard silica gel column chromatography conditions, similarly to imino amide 7 (Fig. 1).

We then examined the asymmetric Friedel-Crafts reaction of imino phosphonate 11 (Table 4). As when using imino amide-type substrate 7 , the addition of indole $\mathbf{8 a}$ proceeded smoothly with good enantioselectivity using a catalytic amount of 9 (entry 1). Both electron-rich and electron-deficient indoles $\mathbf{8 b}-\mathbf{e}$ and $\mathbf{8 j}$ were tolerated (entries 2-6) and indoles $\mathbf{8 g}$ and $\mathbf{8 h}$ having methyl substituents at the 6 or 7 positions gave the desired adducts in good yield with sufficient enantioselectivities (entries 8 and 9). In contrast, 2-and 4-methyl indoles $8 \mathbf{f}$ and $\mathbf{i}$ gave diminished stereoselectivities (entries 7 and 10). Furthermore, not only indoles, but also pyrroles $\mathbf{8 k}-\mathbf{m}$ could be used as nucleophiles (entries 11-13). Our observation that $N$-methylated indole $\mathbf{8 n}$ proceeded sluggishly with low enantioselectivity indicates the important role of the indole proton in forming the substrate-catalyst complex (entry 14).

We next attempted to further transform adduct 15a (Chart 3). The Nps group of 15a was readily removed using 2-PySH. ${ }^{36)}$ Introduction of the Fmoc group followed by debenzylation mediated by $\mathrm{NaI}$ afforded Fmoc amino phosphonic acid mono benzyl ester 17, which is a useful intermediate for synthesizing various biologically active amino phosphonic acid derivatives, without racemization.

\section{Synthesis of Non-canonical Amino Acid-Containing Peptides via Direct Organic Reactions with Peptides}

Peptides have unique biological activities depending on their amino acid sequence. ${ }^{37)}$ If the constituent amino acids are extended to non-canonical variants, the diversity of the chemical structure of the peptide dramatically increases, thereby enhancing the potential for obtaining efficient drug candidates. ${ }^{38,39)}$ Chemical transformation of the side chain of the requisite site of the peptidic substrate is the most straightforward strategy for preparing such compounds. Chemical reactions to obtain peptidic compounds, however, are limited to relatively simple reactions such as the condensation or deprotection of certain protective groups, e.g., tert-butoxycarbonyl (Boc), 9-fluorenylmethyloxycarbonyl (Fmoc), and benzyloxycarbonyl (Cbz) groups. Peptides are relatively polar compared 
Table 4. Asymmetric Friedel-Crafts Reaction of $\mathbf{1 1}^{\mathrm{a}}$

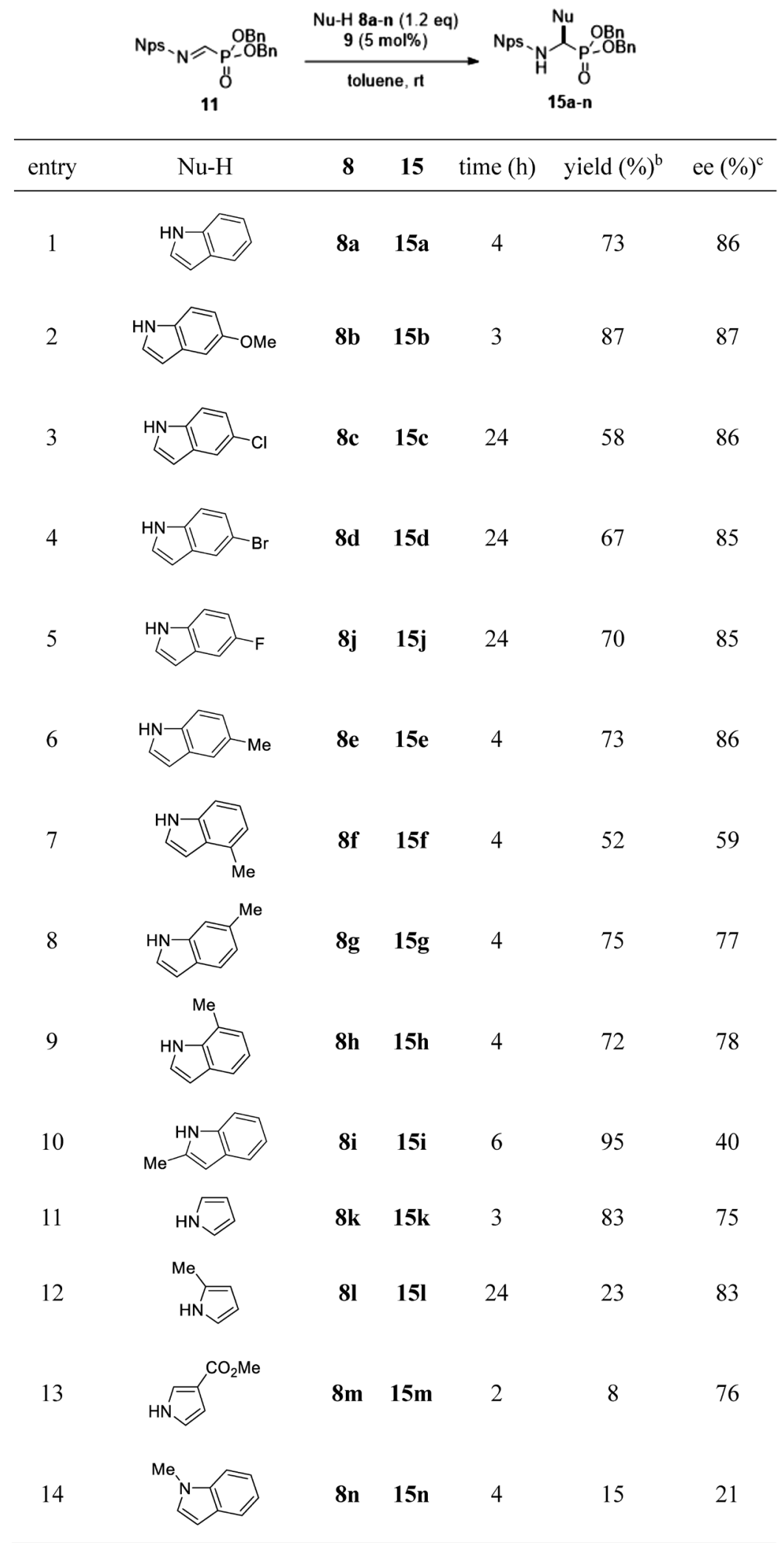

${ }^{a}$ The reaction was performed with 11 (1.0 equiv), 8 (1.2 equiv), and $\mathbf{9}(5 \mathrm{~mol} \%)$ in toluene at room temperature. ${ }^{\mathrm{b}}$ Isolated yield. ${ }^{\mathrm{c}}$ Determined by chiral HPLC analysis.

with most small molecules; therefore, application to a standard liquid phase reaction is difficult, and the classical strategy for using a peptidic substrate relies on solid-state synthesis using a polymeric resin support. ${ }^{40)}$ Such a synthetic strategy has the advantage of purifying the product but the disadvantage of a low reaction efficacy, and thus it is difficult to apply to most 

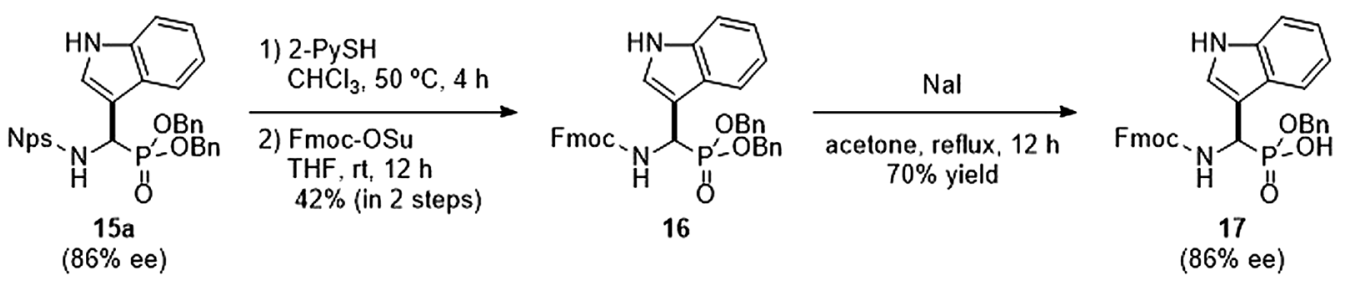

Chart 3. Deprotection of 15a for the Synthesis of Fmoc-Protected Phosphonic Acid Monoester 17

A. resin-supported peptide

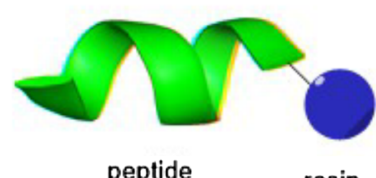

resin

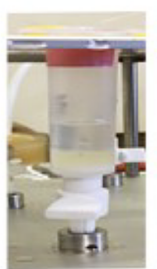

insoluble in most organic solvents difficult to apply to the standard organic reactions
B. Hydrophobic anchor-tagged peptide

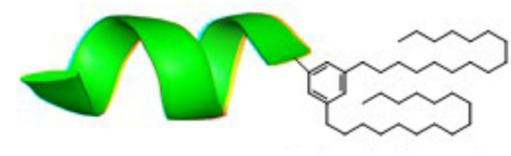

hydrophobic anchor

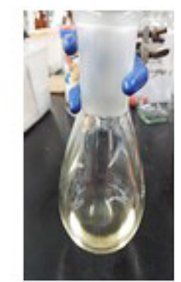

soluble in most organic solvents easy to apply to the standard organic reactions

Fig. 2. Comparison of the Resin-Supported Peptide and Hydrophobic Anchor-Tagged Peptide

(Color figure can be accessed in the online version.)

of the standard organic reactions (Fig. 2-A). We hypothesized that overcoming the problem of solubility in a standard organic solvent would address this issue. To realize this, we focused on using the hydrophobic anchor reported by Tamiaki et al., ${ }^{41)}$ Takahashi et al., ${ }^{42)}$ and Chiba and colleagues, ${ }^{43)}$ independently. The hydrophobic anchor moiety bearing long alkyl chains makes the compound soluble in a less-polar organic solvent such as $\mathrm{CHCl}_{3}$, toluene, or tetrahydrofuran (THF). We anticipated that the standard chemical reactions would be applicable to peptides bearing a hydrophobic anchor (Fig. 2-B).

3.1. Synthesis of Stapled Peptide via Direct Ringclosing Metathesis Since Grubbs reported a highly reactive and stable catalyst for ring-closing metathesis (RCM), RCM has been regarded as one of the most powerful methods for constructing a ring structure. ${ }^{44)}$ This reaction applied to a peptide bearing two olefin-containing residues provides access to a stapled peptide, in which two of the side chains of the peptide are connected via a $\mathrm{C}-\mathrm{C}$ bond to stabilize the threedimensional structure of the peptide, which often possesses outstanding biological activities. ${ }^{45-47)}$ These peptides can be prepared by RCM of a peptide bearing two olefin structure on its side chains, followed by reduction of the resulting cyclic olefin. The efficacy of these reactions toward conventional resin-supported peptides, however, is generally low due to the heterogeneity of the reactions. ${ }^{48)}$ We applied these transformations to hydrophobic-anchor-tagged peptide $\mathbf{1 8}$ in solution phase ${ }^{49)}$ (Chart 4). We realized RCM using a second generation Grubbs catalyst $\mathbf{1 9}^{50}$ in $\mathrm{CHCl}_{3}$ under homogeneous conditions. The reaction proceeded smoothly within $1 \mathrm{~h}$, and peptide 20 was obtained as a mixture of $E / Z$-isomers. After hydrogenation of the olefin moiety followed by global deprotection under acidic conditions, we obtained stapled peptide 21, an analog of the peptide hormone oxytocin ${ }^{51,52)}$ whose $\mathrm{S}-\mathrm{S}$ bond has been replaced with a $\mathrm{C}-\mathrm{C}$ bond.

3.2. Synthesis of Non-canonical Amino Acid-containing Peptides via Direct Asymmetric Addition to Peptides As described in section 2, non-canonical amino acids bearing diverse side-chain structures can be prepared by changing the nucleophiles of the asymmetric addition to $\alpha$-imino carboxylic acid derivatives. Preparation of peptides having these residues can be achieved by installing the units to a growing peptide chain. This conventional strategy requires multiple steps, however, to prepare the corresponding units into an appropriate form. In addition, the condensation step might suffer from epimerization of the non-canonical amino acid unit depending on the side-chain structure. ${ }^{53)}$ We envisioned that if an imino peptide, which possesses an imine moiety at its N-terminus, can be used as substrate instead of $\alpha$-imino carboxylic acid, we could easily access the non-canonical amino acid-containing peptide ${ }^{28}$ (Fig. 3). This strategy could avoid multiple transformation steps and epimerization-prone steps.

An important key to realizing this concept is the preparation of the imino peptide. We used a mild oxidative condition to prepare the $N$-Nps imine described in Chart 1 to produce an $\mathrm{N}$-Nps imino peptide (Chart 5). As expected, the hydrophobic anchor-tagged peptide 23 bearing an Nps glycine unit at its C-terminus was efficiently converted to the $N$-Nps imino peptide 24. The asymmetric Friedel-Crafts reaction with indole 8a catalyzed by BINOL-derived phosphoric acid $\mathbf{9}$ can be applied to the thus-obtained imino peptide $\mathbf{2 4}$ to afford adduct 25 in the same manner as for the $N$-Nps imino amide 7. Removing the Nps group, further elongation, and final deprotection by removing the acid-labile protections by trifluoroacetic acid (TFA) treatment and Pd-mediated removal of the Alloc moiety, produced the desired peptidic compound 26. Although the chemical yield and stereoselectivity were still unsatisfactory, this was the first example of a direct asymmetric reaction to an imino peptide.

\section{Development of Novel Recyclable Asymmetric Cata- lyst}

Asymmetric organocatalysis is a fundamental strategy for synthesizing optically active compounds because they are less-toxic, cost-effective and can be readily operated compared with conventional metal catalysis. ${ }^{54,55)}$ In most cases, however, the catalysts are discarded after each reaction. Thus, 


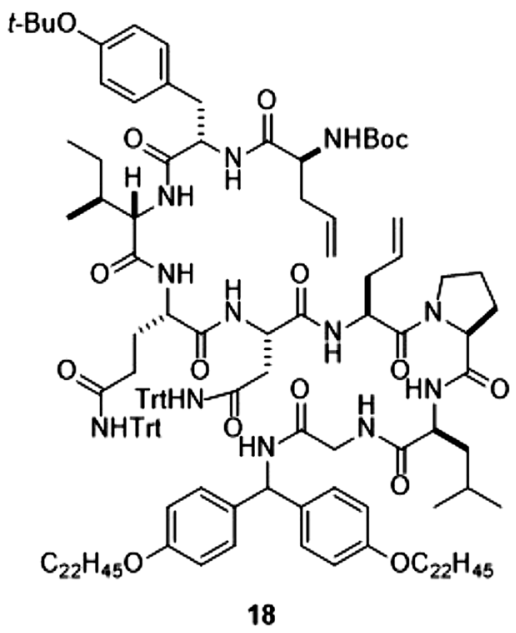

18

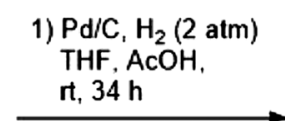

2) TFA, $\mathrm{H}_{2} \mathrm{O}$ i- $\mathrm{Pr}_{3} \mathrm{SiH}$

rt, $1.5 \mathrm{~h}$

$52 \%$ yield (in 3 steps)<smiles>CN1CCN(C)C1[Ge](Cl)(Cl)C(Cl)(Cl)c1ccccc1</smiles>

t-BuO

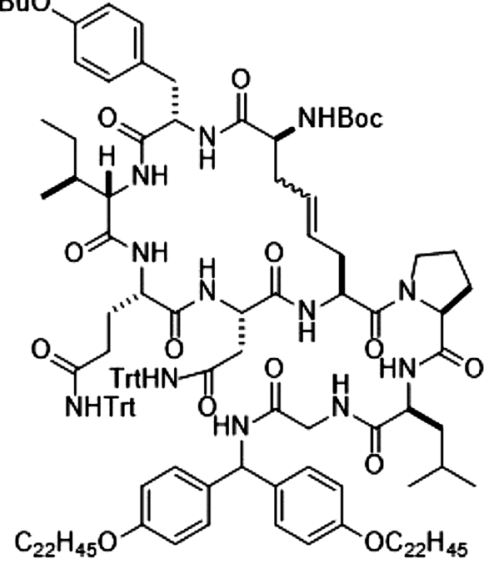

20

Chart 4. Synthesis of the Stapled-Type Oxytocin Analog 21 via Direct RCM of Peptide 18

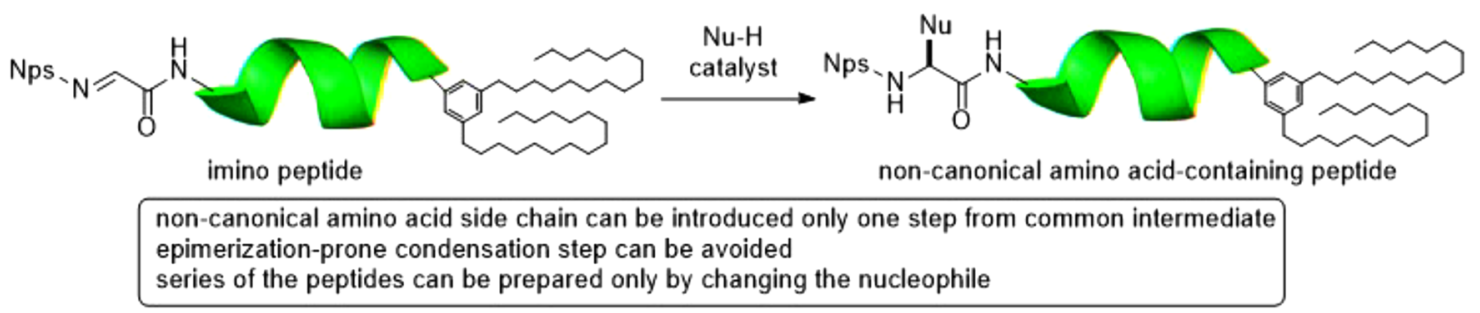

Fig. 3. Concept of Direct Asymmetric Addition to an Imino Peptide

(Color figure can be accessed in the online version.)

systems enabling easy recovery of the organocatalysts have been developed. Binding the catalyst to a polymer resin is one example of these systems. ${ }^{56,57)}$ These catalysts are insoluble in the reaction media, so they can be readily recovered by simple filtration after the reactions and reused in another batch of reactions. Insolubility, however, causes low reactivity. A polyethylene glycol-supported catalyst is a soluble polymersupported catalyst. ${ }^{58,59)}$ In this case, the high solubility sometimes resulted in low recovery efficacy. Recently, perfluorinated alkyl chains were used for a fluorous tag system. ${ }^{60,61)}$ Homogenous forms of perfluorinated alkyl chains can be used in standard organic solvents and recovered by extraction using perfluorinated solvents or chromatography using a perfluorinated stationary phase. Although the fluorous tag system is an effective strategy, it requires expensive perfluorinated compounds to prepare and recover the catalysts. We anticipated that the problems encountered with these conventional recyclable catalysts could be overcome using a hydrophobic anchor as a support for an asymmetric catalyst. ${ }^{62)}$ The concept of the hydrophobic anchor-tagged recyclable catalyst is shown in Fig. 4. The catalyst bearing hydrophobic anchor is expected to be easily prepared from inexpensive starting materials. The asymmetric catalytic reaction can be performed in a less-polar organic solvent in a homogenous manner. After the reaction, removal of the media and addition of a polar solvent would precipitate the catalyst. Then, the division of the precipitate and supernatant by filtration, we can recover the catalyst as the precipitated solid and obtain the desired compound in the filtrate. We expected that the recovered catalyst would be reusable in another batch of reactions. 

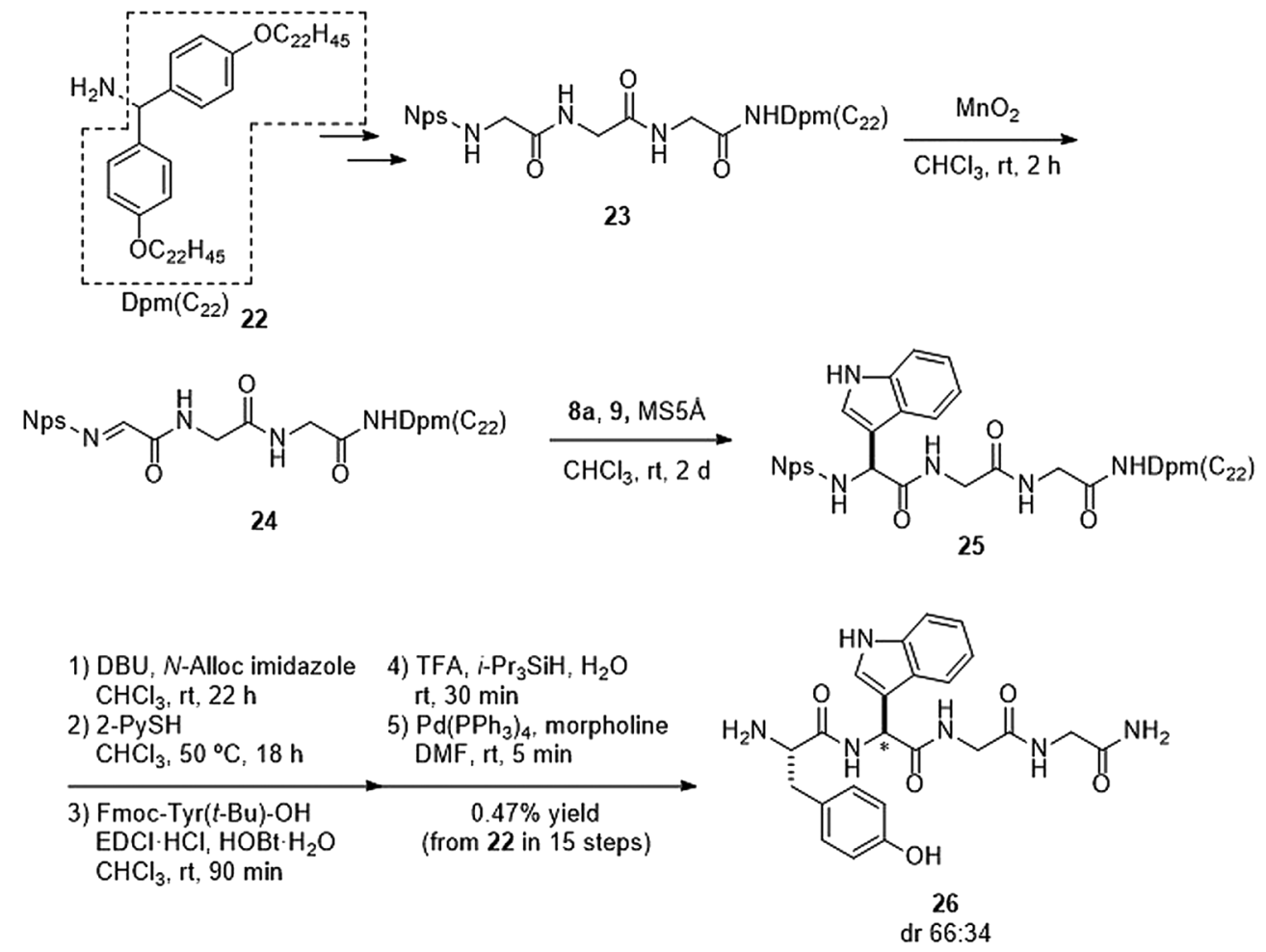

Chart 5. Preparation and Direct Asymmetric Friedel-Crafts Reaction of Imino Peptide $\mathbf{2 4}$ for the Synthesis of Indolyl-Glycine-Containing Peptide

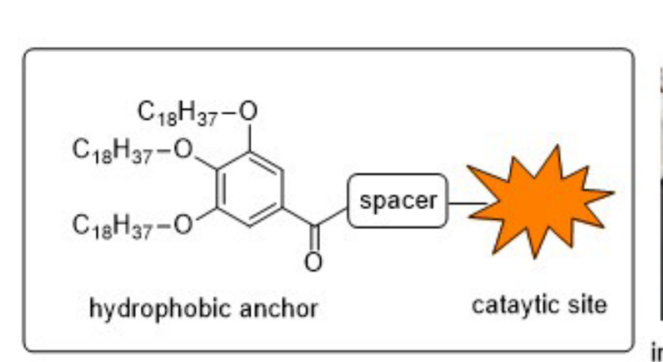

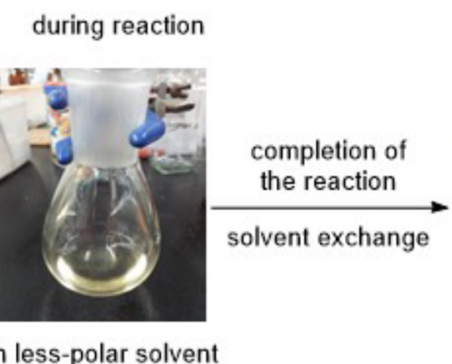

in less-polar solvent

(soluble) after reaction

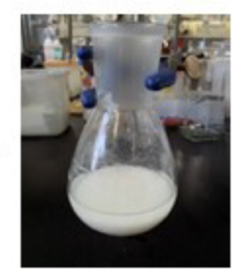

in polar solvent

(insoluble)

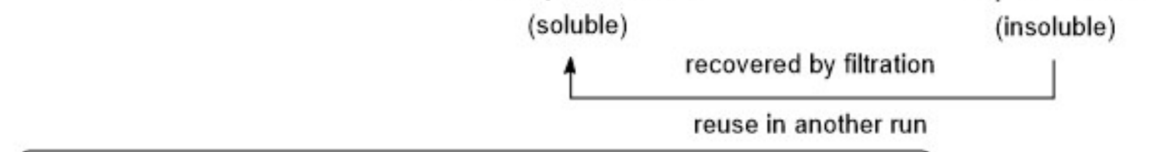

Features of the hydrophobic anchor-tagged catalyst

available from inexpensive starting materials

efficiently activates the reaction in homogeneous media

can be readliy recovered only by solvent exchange and simple filtration

reusable in another run after recovery

Fig. 4. Concept of the Hydrophobic Anchor-Tagged Recyclable Organocatalyst

(Color figure can be accessed in the online version.)

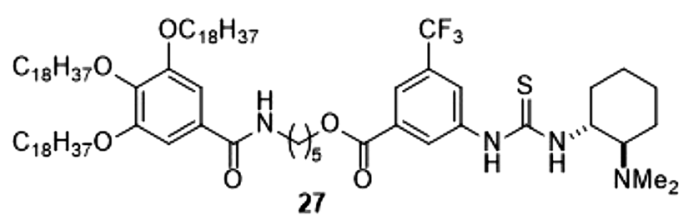

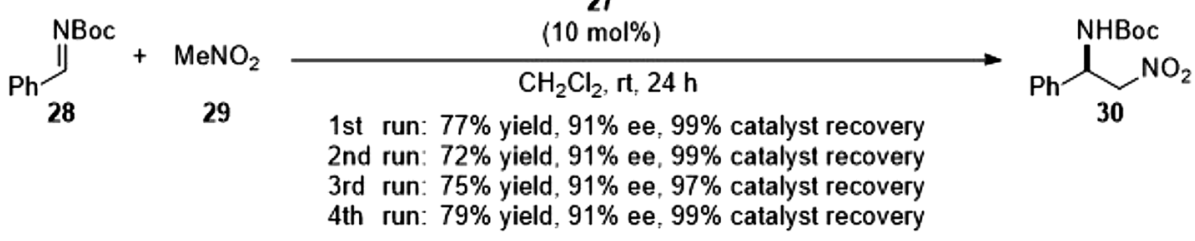

Chart 6. Asymmetric Aza-Henry Reaction of $N$-Boc Imine $\mathbf{2 8}$ and Nitromethane $\mathbf{2 9}$ Catalyzed by Hydrophobic Anchor-Tagged Recyclable Amino Thiourea 27 
We prepared the hydrophobic anchor-tagged amino thiourea catalyst 27 inspired by Takemoto's amino thiourea catalyst $4^{21}$ ) and tested its reactivity and recyclability in the Aza-Henry reaction of $\mathrm{N}$-Boc imine 28 and nitromethane 29 (Chart 6). Our recyclable catalyst gave the adduct $\mathbf{3 0}$ in good chemical yield with high enantioselectivity, comparable to the case using the original catalyst $4 .^{63)}$ As expected, catalyst 27 was recovered with high efficacy by solvent exchange and filtration, and the recovered catalyst could also be used in another run without loss of reactivity or enantioselectivity.

\section{Conclusion}

We described our recent progress toward the synthesis of non-canonical amino acid-related compounds. Using the $\mathrm{MnO}_{2}$-mediated oxidation system, we developed a convenient method for preparing $N$-PMP imino carboxylic acid derivatives, a common precursor of non-canonical amino acids. Applying the same approach to $N$-Nps imine, which has the advantages of better stability and lability for removing the protection relative to the $N$-PMP system. We also achieved the synthesis of non-canonical amino acid-containing peptides. Using hydrophobic anchor-tagged peptides, we demonstrated direct chemical transformations, such as RCM and asymmetric Friedel-Crafts-type reactions, of peptidic substrates. Furthermore, we developed a novel recyclable catalytic system using a hydrophobic anchor-tagged catalyst, which could be readily prepared and recycled without using expensive materials. Further studies, including the development of genuinely efficient novel drug candidates based on non-canonical amino acid derivatives provided by our newly devised strategy are currently underway.

Acknowledgments I would like to express my deepest gratitude to Prof. Ken-ichi Yamada (Tokushima University) and Prof. Akira Otaka (Tokushima University) for helpful discussions and advice for achieving the research described in this review. I would also thank Prof. Akira Shigenaga (Fukuyama University) and my collaborators, especially Dr. Keisuke Aihara, Dr. Takahisa Jichu, Mr. Kodai Nishida, and $\mathrm{Mr}$. Takuya Sakakibara for supporting this research. The research was financially supported in part by a Grant-in-Aid for Young Scientists (B) (JP16K18845 and JP18K14869) from JSPS, a research grant from Takeda Science Foundation, Shionogi \& Co., Ltd. Award in Synthetic Organic Chemistry, the research program for the development of an intelligent Tokushima artificial exosome (iTEX) and the Research Clusters program (No. 1802001) from Tokushima University.

Conflict of Interest $\mathrm{MnO}_{2}$ used for the synthesis of $N$-Nps imines 7, 11, and 24 was a gift from Chuo Denko.

\section{References}

1) Blaskovich M. A. T., J. Med. Chem., 59, 10807-10836 (2016).

2) Stevenazzi A., Marchini M., Sandrone G., Vergani B., Lattanzio M., Bioorg. Med. Chem. Lett., 24, 5349-5356 (2014).

3) Agirre M., Arrieta A., Arrastia I., Cossío F. P., Chem. Asian J., 14, 44-66 (2019)

4) Walker S., Chen L., Hu Y., Rew Y., Shin D., Boger D. L., Chem. Rev., 105, 449-476 (2005).

5) Fisher J. F., Meroueh S. O., Mobashery S., Chem. Rev., 105, 395 $424(2005)$.
6) Moloney M. G., Nat. Prod. Rep., 16, 485-498 (1999).

7) Evans D. A., Nelson S. G., J. Am. Chem. Soc., 119, 6452-6453 (1997).

8) Wang H., Wang K., Ren Y., Li N., Tang B., Zhao G., Adv. Synth. Catal., 359, 1819-1824 (2017).

9) Hashimoto T., Maruoka K., Chem. Rev., 107, 5656-5682 (2007).

10) Taggi A. E., Hafez A. M., Lectka T., Acc. Chem. Res., 36, 10-19 (2003).

11) Takeshima A., Kano T., Maruoka K., Org. Lett., 21, 8071-8074 (2019).

12) Lee H.-J., Arumugam N., Almansour A. I., Kumar R. S., Maruoka K., Synlett, 30, 401-404 (2019).

13) Perera S., Sinha D., Rana N. K., Trieu-Do V., Zhao J. C.-G., J. Org. Chem., 78, 10947-10953 (2013).

14) Jiang J., Ma X., Liu S., Qian Y., Lv F., Qiu L., Wu X., Hu W., Chem. Commun., 49, 4238-4240 (2013).

15) Zhang G., Zhang Y., Wang R., Angew. Chem. Int. Ed., 50, 10429 10432 (2011).

16) Zhao L., Baslé O., Li C.-J., Proc. Natl. Acad. Sci. U.S.A., 106, 4106-4111 (2009)

17) Sonobe T., Oisaki K., Kanai M., Chem. Sci., 3, 3249-3255 (2012).

18) Inokuma T., Jichu T., Nishida K., Shigenaga A., Otaka A., Chem. Pharm. Bull., 65, 573-581 (2017).

19) Soldatenkov A. T., Polyanskii K. B., Kolydina N. M., Soldatova S. A., Chem. Heterocycl. Compd., 45, 633-657 (2009).

20) Hirano M., Yakabe S., Chikamori H., Clark J. H., Morimoto T., J. Chem. Res., 1998, 770-771 (1998).

21) Okino T., Hoashi T., Takemoto Y., J. Am. Chem. Soc., 125, $12672-$ 12673 (2003).

22) Takaya J., Kagoshima H., Akiyama T., Org. Lett., 2, 1577-1579 (2000).

23) Ibrahem I., Casas J., Córdova A., Angew. Chem. Int. Ed., 43, 65286531 (2004)

24) Verkade J. M. M., van Hemert L. J. C., Quaedflieg P. J. L. M., A1sters P. L., van Delft F. L., Rutjes F. P. J. T., Tetrahedron Lett., 47, 8109-8113 (2006).

25) Zervas L., Borovas D., Gazis E., J. Am. Chem. Soc., 85, 3660-3666 (1963).

26) Kessler W., Iselin B., Helv. Chim. Acta, 49, 1330-1344 (1966).

27) Wüensch E., Moroder L., Göhring-Romani S., Musiol H.-J. Göhring W., Bovermann G., Int. J. Pept. Protein Res., 32, 368-383 (1988).

28) Inokuma T., Nishida K., Shigenaga A., Yamada K., Otaka A., Heterocycles, 97, 1269-1287 (2018).

29) Akiyama T., Itoh J., Yokota K., Fuchiba K., Angew. Chem. Int. Ed., 43, 1566-1568 (2004).

30) Uraguchi D., Terada M., J. Am. Chem. Soc., 126, 5356-5357 (2004).

31) Mucha A., Kafarski P., Berlicki Ł., J. Med. Chem., 54, 5955-5980 (2011).

32) Kobayashi S., Kiyohara H., Nakamura Y., Matsubara R., J. Am. Chem. Soc., 126, 6558-6559 (2004).

33) Maestro A., de Marigorta E. M., Palacios F., Vicario J., J. Org. Chem., 84, 1094-1102 (2019).

34) Dodda R., Zhao C.-C., Tetrahedron Lett., 48, 4339-4342 (2007).

35) Inokuma T., Sakakibara T., Someno T., Masui K., Shigenaga A., Otaka A., Yamada K., Chem. Eur. J., 25, 13829-13832 (2019).

36) Stern M., Warshawsky A., Fridkin M., Int. J. Pept. Protein Res., 13, 315-319 (1979).

37) Otvos L. Jr., Wade J. D., Front. Chem, 2, 62 (2014).

38) Fosgerau K., Hoffmann T., Drug Discov. Today, 20, 122-128 (2015).

39) Ding Y., Ting J. P., Liu J., Al-Azzam S., Pandya P., Afshar S., Amino Acids, 52, 1207-1226 (2020).

40) Amblard M., Fehrentz J.-A., Martinez J., Subra G., Mol. Biotechnol., 33, 239-254 (2006).

41) Tamiaki H., Obata T., Azefu Y., Toma K., Bull. Chem. Soc. Jpn., 74, 733-738 (2001). 
42) Takahashi D., Yano T., Fukui T., Org. Lett., 14, 4514-4517 (2012).

43) Tana G., Kitada S., Fujita S., Okada Y., Kim S., Chiba K., Chem. Commun., 46, 8219-8221 (2010).

44) Schwab P., France M. B., Ziller J. W., Grubbs R. H., Angew. Chem. Int. Ed. Engl., 34, 2039-2041 (1995).

45) He Y., Chen D., Zheng W., Oncogene, 34, 5685-5698 (2015).

46) Verdine G. L., Hilinski G. J., Methods Enzymol., 503, 3-33 (2012).

47) Lau Y. H., de Andrade P., Wu Y., Spring D. R., Chem. Soc. Rev., 44, 91-102 (2015).

48) Schafmeister C. E., Po J., Verdine G. L., J. Am. Chem. Soc., 122, 5891-5892 (2000).

49) Aihara K., Komiya C., Shigenaga A., Inokuma T., Takahashi D., Otaka A., Org. Lett., 17, 696-699 (2015).

50) Scholl M., Ding S., Lee C. W., Grubbs R. H., Org. Lett., 1, 953-956 (1999).

51) Simpson K. R., J. Midwifery Womens Health, 56, 214-221 (2011).

52) Viero C., Shibuya I., Kitamura N., Verkhratsky A., Fujihara H., Katoh A., Ueta Y., Zingg H. H., Chvatal A., Sykova E., Dayanithi G., CNS Neurosci. Ther., 16, e138-e156 (2010).

53) Miyazawa T., Otomatsu T., Yamada T., Kuwata S., Int. J. Pept. Pro- tein Res., 39, 229-236 (1992).

54) Xiang S.-H., Tan B., Nat. Commun., 11, 3786 (2020).

55) Lassaletta J. M., Nat. Commun., 11, 3787 (2020).

56) Andrés J. M., Ceballos M., Maestro A., Sanz I., Pedrosa R., Beilstein J. Org. Chem., 12, 628-635 (2016).

57) Malkov A. V., Figlus M., Kočovský P., J. Org. Chem., 73, 39853995 (2008).

58) Benaglia M., Cinquini M., Cozzi F., Puglisi A., Celentano G., $A d v$. Synth. Catal., 344, 533-542 (2002).

59) Miyabe H., Tuchida S., Yamauchi M., Takemoto Y., Synthesis, 3295-3300 (2006).

60) Zu L., Li H., Wang J., Yu X., Wang W., Tetrahedron Lett., 47, 5131-5134 (2006).

61) Huang X., Yi W.-B., Ahad D., Zhang W., Tetrahedron Lett., 54, 6064-6066 (2013).

62) Jichu T., Inokuma T., Aihara K., Kohiki T., Nishidsa K., Shigenaga A., Yamada K., Otaka A., ChemCatChem, 10, 3402-3405 (2018).

63) Xu X., Furukawa T., Okino T., Miyabe H., Takemoto Y., Chem. Eur. J., 12, 466-476 (2005). 